\title{
Physicochemical properties of Kalahari melon seed oil following extractions using solvent and aqueous enzymatic methods.
}

\begin{abstract}
The physico-chemical properties of oil from Kalahari melon seed were determined following extraction with petroleum ether and aqueous-enzymatic methods. Two different enzymes Flavourzyme $1000 \mathrm{~L}$ and Neutrase $0.8 \mathrm{~L}$ were separately used during aqueous-enzymatic method. The free fatty acid, peroxide, iodine and the saponification values of the oils extracted using the methods were found to be significantly $(\mathrm{P}<0.05)$ different. The melting point of the oils extracted was in the range of $) 18.7 \mathrm{C}$ to $) 17.5 \mathrm{C}$ and no significant $(\mathrm{P}>0.05)$ difference between the oil obtained from solvent and aqueous-enzymatic extractions was observed. Enzyme-extracted oil tended to be light-coloured and more yellow in colour compared with solvent-extracted oil. The predominant fatty acids in the extracted oils were linoleic acid (62.2-63.1\%), with some oleic (16.8-17.1\%), palmitic (11.4-12.4\%), stearic $(7.5-8.1 \%)$, linolenic $(0.7-1.2 \%)$ and eicosenoic $(0.3 \%)$. Phenolic acids in enzyme-extracted oils were comparable to the solvent-extracted oil. The oils extracted with these two methods were differed in the composition of their phytosterol and tocopherol contents, but no significant $(\mathrm{P}>0.05)$ difference between the two enzyme-extracted oils was observed.
\end{abstract}

Keyword: Aqueous-enzymatic oil extraction; Chemical composition; Flavourzyme; Kalahari melon seed; Neutrase; Oil extraction; Ooilseeds; Phenolic acid; Phytosterol; Thermal properties; Tocopherol. 